\title{
МЕТОДОЛОГИЯ АЛГОРИТМА ОРГАНИЗАЦИОННОЙ ПОДДЕРЖКИ ПРЕДПРИНИМАТЕЛЬСТВА В РОССИИ "
}

\author{
(c) 2020 Мельникова Любовь Анатольевна \\ кандидат экономических наук, доцент департамента аудита и корпоративной отчетности \\ Финансовый университет при Правительстве РФ, Россия, Москва \\ E-mail: lamelnikova@fa.ru
}

(c) 2020 Назаров Дмитрий Владимирович

кандидат экономических наук, доцент департамента бизнес-аналитики

Финансовый университет при Правительстве РФ, Россия, Москва

E-mail: dvnazarov@fa.ru

\section{(c) 2020 Кеворкова Жанна Аракеловна}

доктор экономических наук, профессор департамента аудита и корпоративной отчетности Финансовый университет при Правительстве РФ, Россия, Москва

Российская Федерация, руководствуясь требованиями времени, четко определила основные цели государственной политики в сфере организационной поддержки предпринимательства. Первоочередной целью государством была выделена проблема необходимой стабилизации социальной обстановки в обществе, направленная на сглаживание социальных конфликтов, а также установление диалога между государством и гражданами в целях поддержки предпринимательства. С целью поддержки предпринимательства государство предпринимает ряд мер, направленных на обеспечение социально-экономической стабильности, а также посредством воздействия на рынок труда и на трудовую сферу повышает социальную защищенность каждого гражданина в сфере трудоустройства и занятости.

В Российской Федерации осуществление государственной политики занятости населения происходит при помощи мер таких политик, как: налоговой, социальной, инвестиционной и финансовокредитной. Такие меры направлены на рост мобильности трудовых ресурсов, стимулирование «гибких» режимов труда, разработку новых технологий, всестороннюю поддержку малого бизнеса и начинающих предпринимателей, а также на целесообразное размещение производительных сил в стране. Безусловно, вышеобозначенные меры будут способствовать развитию и сохранению системы занятости населения в сфере предпринимательства.

Ключевые слова: алгоритм, государственная поддержка, предпринимательство, система, стимулирование, сфера, экономика.

При выполнении приоритетных задач в любой сфере жизни общества, государство разрабатывает и приводит в исполнение ряд федеральных и региональных программ. В Российской Федерации существуют программы, содействующие повышению организационной поддержки предпринимательства, основанные на сложившейся ситуации на рынке труда, наличествующих прогнозах в сфере предпринимательства.

Механизмами по осуществлению государственной политики в сфере предпринимательства определяются: контроль деятельности органов власти всех уровней, привлечение фи- нансовых средств, а также привлечение кадров. Разработку, организацию, реализацию и контроль за исполнением программ в сфере занятости осуществляют органы государственной власти.

Вопросами государственной поддержки, организации, методологии и занятости населения посвящены научные труды ведущих специалистов, а именно: Е.М.Бухвальд, А.В.Виленский, О.В.Лылова [1-4], Е.С.Дашкова, Н.В.Дорохова [5-6], Т.И.Дуженко [7], Л.Г.Иогман [8], А.И.Костяев [9] и др.

Для того, чтобы выполнить основные задачи

\footnotetext{
* Исследование выполнено в рамках научного проекта ГПХ ВТК-ГЗ-ПИ-35-20 «Обеспечение диверсификации занятости и разработка механизмов поддержки инициатив населения в сфере предпринимательства»
} 
государственной политики в сфере предпринимательства необходимо реализовать ряд задач (см. рисунок 1).

В свою очередь, если начинающему предпринимателю необходима государственная финансовая поддержка, то ему приходится пройти три этапа для ее получения (см. рисунок 2).

Начальный этап заключается в том, что на местном уровне фонд занятости, органы местного самоуправления совместно с территориальным департаментом инвестиций и предпринимательства отбирают безработных граждан, зарегистрированных в этом статусе и получающих пособие по безработице, обучают отобранных граждан основам ведения собственного бизнеса. Далее выделяются денежные средства на открытие собственного бизнеса и субсидии отправляют в организации инфраструктуры поддержки предпринимательства. В департа- мент предпринимательства и инвестиций, а также в органы местного самоуправления отправляются списки предпринимателей, открывших свой бизнес.

Промежуточный этап представляет собой некий консультационный блок. Так, организации инфраструктуры, органы местного самоуправления и бизнес-инкубаторы оказывают всестороннюю помощь начинающим предпринимателям, проводят консультации в сфере предпринимательства, как вести собственный бизнес, осуществляют сопровождение деятельности предпринимателя. Также в их компетенцию входит оказание помощи в подготовке документов, необходимых для получения субсидии в рамках муниципальной или областной программы развития малого и среднего бизнеса.

Завершающим этапом является подбор нужных сотрудников для осуществления уставной

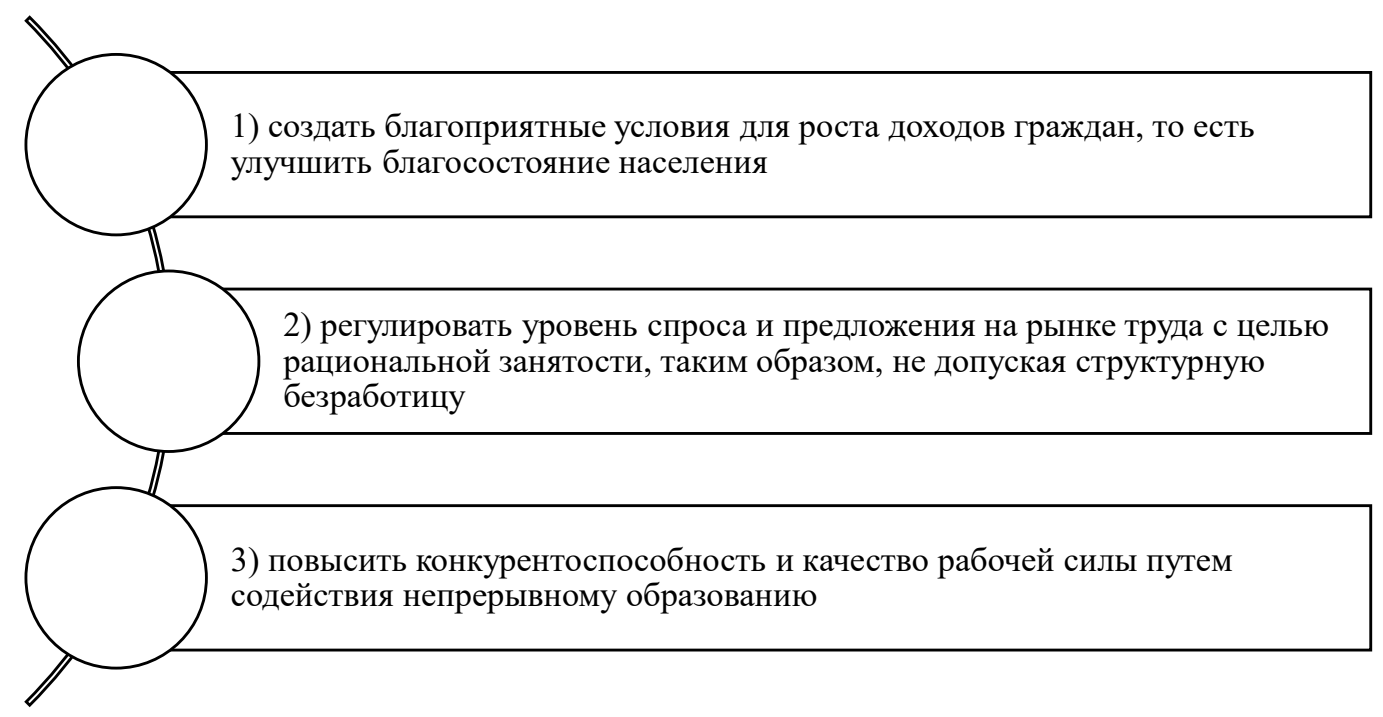

Рисунок 1. Основные задачи государственной политики в сфере предпринимательства

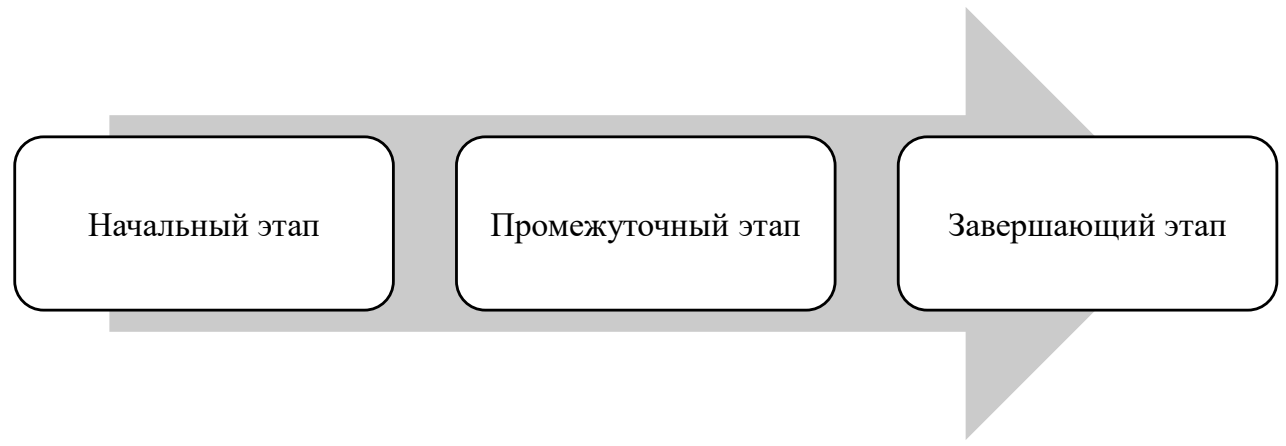

Рисунок 2. Основные этапы получения государственной поддержки для предпринимателя 
деятельности начинающим предпринимателям. Персонал подбирается из числа бывших безработных. В городах и районных центрах этот поиск осуществляется с помощью центра занятости населения.

Однако, надо учитывать факт того, что на государственные программы содействия малому и среднему бизнесу в 2020 году могут рассчитывать те компании и предприниматели, которые будут отвечать конкретным критериям отбора.

Если все критерии и требования соблюдены, предприниматели должны разработать и представить подробный бизнес-план. Средства, полученные от государства в виде субсидий в обязательном порядке должны расходоваться по назначению: на покупку сырья и оборудования, либо на компенсацию расходов по аренде и прочее. Стоит отметить, что на протяжении определенного времени, необходимо предоставлять отчеты, по расходованию средств в те инстанции, кто оказал помощь в виде субсидии, например, в администрацию города.

Методология государственной поддержки предпринимательства в России осуществляется и на уровне регионов при помощи различных инструментов и механизмов. Меры содействия определяются на уровне разных инстанций, к числу которых следует отнести: городскую администрацию, торгово-промышленную палату и т.д. Городская администрация обеспечивает предпринимателя необходимой информацией, осуществляет выдачу субсидий. Торговопромышленная палата - проводит бесплатные консультации по вопросам касательно развития бизнеса, маркетинга и права участия в различных федеральных и международных выставках.

Предпринимательству оказывается государственная финансовая помощь которая осуществляется не только на открытие бизнеса, но и на дальнейшее его развитие, посредством субсидирования.

Подведем итог вышеизложенному. Государственная политика в отношении российского предпринимательства проводится достаточно эффективно, разрабатываются и внедряются различные государственные программы по поддержке (финансовой, консультационной и т.д.) малого и среднего бизнеса, создаются новые рабочие места, сокращается уровень безработицы в стране, что в свою очередь положительно влияет на экономическое развитие России.

\section{Библиографический список}

1. Бухвальд Е.М., Виленский А. В., Лылова О.В. Поиск новизны в приоритетном национальном проекте «Малое и среднее предпринимательство и поддержка индивидуальной предпринимательской инициативы 2024 Г.» // Вестник Владимирского государственного университета имени Александра Григорьевича и Николая Григорьевича Столетовых. Серия: Экономические науки. 2019. № 1 (19). С. 109-120.

2. Виленский А.В. Динамика занятых в сфере МСП в российских регионах как исходный рубеж реализации приоритетного национального проекта «Малое и среднее предпринимательство и поддержка индивидуальной предпринимательской инициативы» // Проблемы развития территории. 2018. № 6 (98). С. 74-87.

3. Виленский A.B. Динамика занятых в сфере МСП в российских регионах как исходный рубеж реализации приоритетного национального проекта «Малое и среднее предпринимательство и поддержка индивидуальной предпринимательской инициативы» // Проблемы развития территории. 2018. № 6 (98). С. $74-87$.

4. Виленский А.В., Лылова О.В. Поиск стратегии социального развития регионов РФ // Экономика: вчера, сегодня, завтра. 2017. Т. 7. № 1А. С. 153-167.

5. Дашкова Е.С., Дорохова Н.В. Занятость населения в России: современные тенденции: монография.-Воронеж: Воронежский ЦНТИ - филиал ФГБУ «РА» Минэнерго России, 2013. - 88 с

6. Дашкова Е.С., Дорохова Н.В. Нестандартная занятость в России // Вестник Воронежского государственного университета. Серия: Экономика и управление.- 2014.- № 2.-С. 19-21.

7. Дуженко Т. И. Диверсификация региональной экономики на основе развития социальной инфраструктуры. Автореф. Sci. (Эконом.) Диссертация, Новосибирск, 2015. URL: http://econom.nsc.ru/ieie/ Новости / zashiti / персоналии / 2015 / dugenko / dissert.pdf. Дата обращения: 20.04.2020 г.

8. Иогман Л.Г. Стратегия диверсификации региональной экономики, экон. Соц. Перемены: Факты, Тенденции, Прогноз, 2008, № . 1 (1), с. 78-91.

9. Костяев А.И. «Диверсификация сельской занятости в условиях аграрной модернизации» URL: https:// cyberleninka.ru/article/n/diversifikatsiya-selskoy-zanyatosti-v-usloviyah-agrarnoy-modernizatsii. Дата обращения: 30.04.2020 г. 